\title{
HUBUNGAN MENGKONSUMSI TABLET FE DENGAN KEJADIAN KONSTIPASI PADA IBU HAMIL DI DESA BANDAR KECAMATAN BANDAR KABUPATEN PACITAN \\ Catur Wulandari ${ }^{1)}$, Wulan Ayu Fitria ${ }^{2)}$ \\ Akbid Harapan Mulya Ponorogo ${ }^{1) 2)}$ \\ Email: cawulan8@gmail.com ${ }^{1)}$
}

\begin{abstract}
Consumption of iron tablet 1 tablet per day during pregnancy can cause constipation. Based on the results of preliminary study in the Bandar Village, Pacitan through interviews with 14 pregnant women there were 12 pregnant women who consumed iron tablet regularly and 8 pregnant women complain of difficulty to defecate while not experiencing constipation 4 pregnant women. From two pregnant women who did not consume fe tablets they didn't get constipation.

The purpose of this study was to determine the relationship consuming Fe tablet with constipation in pregnant women. This type of research is quantitative with cross sectional design conducted in March 2016. The population of all pregnant women in Bandar Village Bandar Subdistrict District of Pacitan as many as 33 pregnant women. The respondents ware all pregnant women in the Bandar Village Bandar district Pacitan. Using total sampling technique, the research was conducted on March 1 until March 30, 2016. The variable in this study is the fe tablet intake and incidence of constipation. The research instrument used was observation about fe tablet consumption and interviewing about incidence of constipation. The data were tabulated and analyzed using a statistical test Chi Square test determined significant with $p>$ 0.05 .

From the results showed that majority of 19 pregnant women (57.5\%) consume iron tablet regularly, and majority of 18 pregnant women (54.5\%) got constipation. There was a relationship consuming Fe tablet constipation with in pregnant women in the Bandar Village district of Pacitan. Evidenced by the significant level of 0.000>0.05 so that Ho refused.

Based on the results of the study, the researcher suggested to health workers to provide counseling to pregnant women about how to consume tablets fe correetly and balanced with foods contaiming high in fiber.
\end{abstract}

Keywords: Fe tablets, Constipation, Pregnancy.

\section{PENDAHULUAN}

Tablet zat besi adalah tablet untuk suplementasi penanggulangan konsumsi zat besi yang setiap tablet mengandung $320 \mathrm{mg}$ Fero Sulfat akan setara dengan $60 \mathrm{mg}$ elemental iron dengan $500 \mathrm{mg}$ folic acid. (Pusdiknakes. 2003). Kekurangan zat besi pada kehamilan berakibat pertumbuhan janin nanti tidak optimal dan biasanya akan mengalami kelahiran prematur, jatuh sakit, berat bayi lahir rendah, resiko pendarahan, waktu persalinan dan dapat meningkatkan resiko kematiam ibu dan bayi. Hal ini perlu disadari bahwa suplementasi mengkonsumsi zat besi perlu bagi ibu hamil tetapi dapat menimbulkan efek smping terhadap konstipasi (Pusdiknakes, 2003).
Menurut Badan Kesehatan Dunia (WHO) prevalensi ibu pertambahan usia kehamilan. Di Indonesia tahun 2001 melaporkan 31 wanita (42\%) menderita kekurangan zat besi (WHO, 2007).

Menurut Marisa, dkk (2008) alumnus program study gizi masyarakat dan sumber daya keluarga, diketahui dari 324 wanita hamil terdapat 12\% mengalami konstipasi. Efek samping dari tablet tambah darah antara lain mengakibatkan nyeri lambung, mual, muntah, konstipasi dan diare. Adanya efek samping dari tablet tambah darah ini diduga menyebabkan ibu hamil menjadi enggan dalam mengkonsumsi tablet tambah darah yang diberikan oleh pelayanan kesehatan setempat sehingga 
memperbesar prevanlensi ketidak patuhan ibu hamil dalam mengkonsumsi tablet zat besi (Marisa dkk, 2008).

Konstipasi adalah kesulitan atau hambatan pengeluaran tinja melalui kolon dan rectum, biasanya disertai kesulitan saat buang air besar. Konstipasi disebabkan kontraksi/obstruksi bagian anal dari otot halus dari usus besar dengan adanya jumlah progesteron yang memikat, pergeseran dan penekanan terhadap perut oleh uterus yang membesar mungkin juga penyebab tambahan dalam gerak kerja yang menurun dalam saluran pencernaan sehingga defekasi yang jarang dan jumlah feses yang kurang konsitensinya keras dan kering. Yang sering mengalami konstipasi wanita hamil selama trimester kedua dan ketiga (Piego, 2004).

Menurut Bradley,(2013) dalam penelitian yang dilakukan oleh Lulut Istiqomah yang berjudul Hubungan Mengkonsumsi Table $\mathrm{Fe}$ dengan Kejadian Konstipasi Pada Wanita Hamil Di BPS Pipin Heriyanti Gedung Kiwo Yogyakarta menyatakan, kejadian konstipasi pada ibu hamil mencapai lebih dari $50 \%$. Separuhya dialami pada trimester pertama dan kedua, menurun pada trimester ketiga dan meningkat kembali pada masa nifas. Di Indonesia menurut data survei Indonesian Medical Diagnose 2007 tercatat 64.000 pasien datang ke klinik kandungan dengan keluhan sembelit atau konstipasi. Pada wilayah Jawa Timur pada tahun 2011 terdapat 654.565 total keseluruhan ibu hamil dan terdapat kurang lebih 2.300 ibu hamil dengan konstipasi (BKKBN, 2011). Menurut DINKES Kabupaten Pacitan pada tahun 2017 jumlah ibu hamil yakni 7.377 dan terdapat lebih dari $118 \mathrm{ibu}$ hamil dengan keluhan konstipasi pada tiap bulannya. Berdasarkan data yang diperoleh dari Bidan Desa Bandar, terdapat 70 ibu hamil yang mendapat tablet Fe selama tahun 2016-2017. Pada bulan April tahun 2018 terdapat $33 \mathrm{ibu}$ hamil yang mendapatkan tablet Fe di Desa Bandar Kecamatan Bandar Kabupaten Pacitan.
Berdasarkan studi pendahuluan yang dilakukan peneliti kepada 14 ibu hamil di Desa Bandar Kecamatan Bandar Kabupaten Pacitan, terdapat 12 ibu hamil yang mengkonsumsi tablet fe secara teratur yakni dengan minum 1 kali dalam sehari dengan menggunakan air putih, dan 2 ibu hamil yang tidak mengkonsumsi tablet fe. Dari 12 ibu hamil yang mengkonsumsi tablet $\mathrm{Fe}$ tersebut terdapat $8 \mathrm{ibu}$ hamil mengeluh sulit untuk buang air besar sedangkan yang tidak mengalami kostipasi $4 \mathrm{ibu}$ hamil. Dan dari 2 ibu hamil yang tidak mengkonsumsi tablet fe tidak mengalami susah buang air besar.

Dampak dari terjadinya konstipasi jika tidak segera ditangani akan menurunkan daya tahan tubuh. Mempengaruhi juga psikologis ibu dalam kehamilannya. Kurangnya zat besi dalam kehamilannya tanpa diimbangi asupan zat besi yang adekuat akan berlanjut pada waktu bersalin nanti (Pusdinakes, 2003). Dampak nyata dari ibu hamil di Desa Bandar Kecamatan Bandar Kabupaten Pacitan yang mengalami konstipasi adalah merasa tidak nyaman dikarenakan nyeri perut, sering merasa mual dan muntah karena perut terasa penuh dan mempengaruhi tingkat emosional pada ibu hamil.

Solusinya agar ibu hamil tidak mengalami konstipasi,ibu hamil harus mengkonsumsi tablet fe secara teratur dan benar. Diminun 1 tablet sehari dengan menggunakan air putih atau air jeruk. Selain itu ibu hamil juga harus mengkonsumsi makanan yang berserat seperti sayur-sayuran hijau, buahbuahan.

Berdasarkan latar belakang masalah diatas maka penulis tertarik untuk melakukan penelitian dengan judul "Hubungan Mengkonsumsi Tablet Fe dengan Kejadian Konstipasi Pada Ibu Hamil di Desa Bandar Kecamatan Bandar Kabupaten Pacitan”.

\section{METODE PENELITIAN}

Jenis penelitian ini adalah kuantitatif dengan analitik korelasional yaitu mengkaji hubungan antar variabel. 
Peneliti dapat mencari, menjelaskan suatu hubungan, memperkirakan, menguji berdasarkan teori yang ada (Nursalam, 2003).

Populasi dalam penelitian ini adalah ibu hamil di Desa Bandar Kecamatan Bandar Kabupaten Pacitan yang berjumlah 33 responden. Jumlah sampel dalam penelitian ini adalah semua dari ibu hamil di Desa Bandar Kecamatan Bandar Kabupaten Pacitan yang berjumlah 33 responden. Teknik sampling dalam penelitian ini adalah non probabiliy sampling dengan jenis total sampling.

Untuk mengetahui hubungan konsumsi tablet Fe dengan kejadian konstipasi pada ibu hamil di Desa Bandar Kecamatan Bandar Kabupaten Pacitan akan dianalisis dengan uji statistik " Chi Square Test”. Analisis data ini dilakukan melalui proses komputerisasi dengan bantuan SPSS 20,0 for windows.

\section{HASIL PENELITIAN}

A. Keteraturan Konsumsi Tablet Fe Tabel 1

Distribusi Responden Berdasarkan

Konsumsi Tablet Fe di Desa Bandar

Kecamatan Bandar Kabupaten Pacitan

\begin{tabular}{ccc}
\hline Konsumsi Fe & Jumlah & $\mathbf{( \% )}$ \\
\hline Teratur & 19 & 57,5 \\
\hline Tidak Teratur & 14 & 42,5 \\
\hline Total & 33 & 100 \\
\hline
\end{tabular}

Berdasarkan tabel diatas dari 33 responden yang diteliti sebagian besar 19 responden $(57,5 \%)$ mengkonsumsi tablet fe secara teratur, dan hampir setengahnya 14 responden $(42,4 \%)$ mengkonsumsi tablef fe tidak teratur. B. Konstipasi Pada Ibu Hamil

Tabel 2

Distribusi Responden Berdasarkan Kejadian Konstipasi Pada Ibu Hamil di Desa Bandar Kecamatan Bandar Kabupaten Pacitan

\begin{tabular}{ccc}
\hline Konstipasi & Jumlah & $(\boldsymbol{\%})$ \\
\hline Ya & 18 & 54,5 \\
\hline Tidak & 15 & 45,5 \\
\hline Total & 33 & 100 \\
\hline Berdasarkan & tabel & di atas
\end{tabular}
didapatkan sebagian besar 18 responden $(54,5 \%)$ mengalami konstipasi, dan hampir setengahnya 15 responden $(45,5 \%)$ tidak mengalami konstipasi.

C. Hubungan Mengkonsumsi Tablet Fe Dengan Kejadian Konstipasi

Tabel 3

Tabulasi Silang

Hubungan Mengkonsumsi Tablet Fe Dengan Kejadian Konstipasi

\begin{tabular}{lrrr}
\hline & \multicolumn{2}{c}{ KONSTIPASI } & Total \\
\hline & TIDAK & YA & \\
\hline TDK & 13 & 1 & 14 \\
TERATUR & & & \\
\hline TERATUR & 2 & 17 & 19 \\
\hline Total & 15 & 18 & 33 \\
\hline
\end{tabular}

Berdasarkan tabel diatas dari 33 responden yang diteliti dalam konsumsi tablet Fe secara teratur sebagian besar 17 responden $(57,5 \%)$ adalah mengalami konstipasi, dan sebagian kecil responden yang secara teratur menkonsumsi tablet $\mathrm{Fe}$ sebanyak 2 $(6,06 \%)$ responden tidak mengalami konstipasi. Untuk responden yang tidak teratur dalam konsumsi tablet Fe hampir seluruhnya $13(39,3 \%)$ tidak mengalami konstipasi, dan sebagian dari kecil dari responden yang tidak teratur dalam konsumsi tablet Fe yakni 1 (3,03\%) responden mengalami konstipasi.

D. Analisa Hasil Penelitian

Tabel 4

Tabel Uji Statistik Menggunakan Chi Square Test.

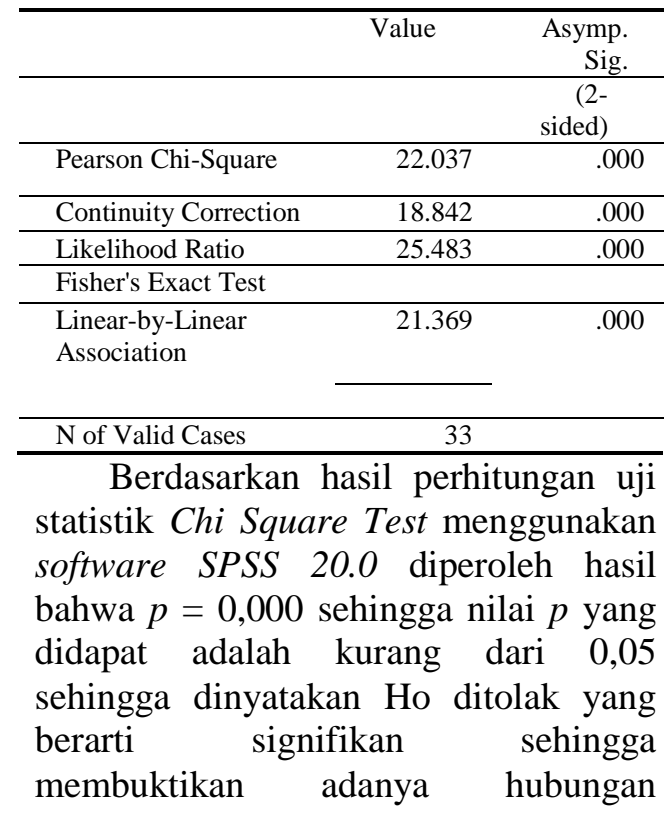


konsumsi tablet fe dengan kejadian konstipasi pada ibu hamil di desa bandar kecamatan bandar kabupaten pacitan.

\section{PEMBAHASAN}

Berdasarkan hasil tabulasi silang antara konsumsi tablet Fe dan kejadian konstipasi dari 33 responden yang diteliti dalam konsumsi tablet Fe secara teratur hampir seluruhnya $17(51,5 \%)$ responden adalah mengalami konstipasi, dan sebagian kecil responden yang secara teratur menkonsumsi tablet $\mathrm{Fe}$ sebanyak $2(6,06 \%)$ responden tidak mengalami konstipasi. Untuk responden yang tidak teratur dalam konsumsi tablet Fe hampir seluruhnya 13 (39,3\%) tidak mengalami konstipasi, dan sebagian dari kecil dari responden yang tidak teratur dalam konsumsi tablet $\mathrm{Fe}$ yakni $1(3,03 \%)$ responden mengalami konstipasi.

Berdasarkan hasil perhitungan uji statistik Chi Square Test menggunakan software SPSS 20.0 diperoleh hasil bahwa $p=0,000$ sehingga nilai $p$ yang didapat adalah kurang dari 0,05 sehingga dinyatakan Ho ditolak yang berarti signifikan sehingga membuktikan adanya hubungan konsumsi tablet fe dengan kejadian konstipasi pada ibu hamil di desa bandar kecamatan bandar kabupaten pacitan. Berdasarkan Uji Statistik Contingency Coefficient dapat diketahui tingkat keeratan hubungan kuat. Hubungan Konsumsi Tablet Fe Dengan Kejadian Konstipasi Pada Ibu Hamil di Desa Bandar Kecamatan Bandar Kabupaten Pacitan mendapatkan nominal value 0.633 sehingga interpretasi korelasi hipotesa dapat dikategorikan dengan tingkat hubungan kuat.

Berdasarkan hasil penelitian terdahulu oleh Lulut Istiqomah yang berjudul Hubungan Mengkonsumsi Table Fe dengan Kejadian Konstipasi Pada Wanita Hamil Di BPS Pipin Heriyanti Gedung Kiwo Yogyakarta dengan tujuan untuk mengetahui Hubungan Mengkonsumsi Table Fe dengan Kejadian Konstipasi Pada Wanita Hamil Di BPS Pipin Heriyanti Gedung Kiwo Yogyakarta tahun 2012. Berdasarkan hasil penelitian di BPS
Pipin Heriyanti Gedungkiwo

Yogyakarta menunjukkan bahwa wanita hamil yang mengkonsumsi tablet $\mathrm{Fe}$ secara teratur beresiko tinggi konstipasi sebesar 47,8\% (22 responden), sebaliknya yang mengkonsumsi tablet Fe dengan tidak teratur atau sesekali persentase terjadi konstipasi rendah sebesar $8,7 \%$ (4 responden). Oleh karena itu dapat disimpulkan bahwa ada hubungan signifikan mengkonsumsi tablet $\mathrm{Fe}$ dengan kejadian konstipasi pada wanita hamil di BPS Pipin Heriyanti Gedungkiwo Yogyakarta tahun 2012. Kesimpulan yang didapatkan adalah ada hubungan yang signifikan antara mengkonsumsi tablet Fe dengan kejadian konstipasi pada wanita hamil di BPS Pipin Heriyanti Gedungkiwo Yogyakarta pada tahun 2012.

Tablet zat besi (iron) diberikan oleh bidan atau dokter biasanya tablet fe tersebut menyebabkan warna feses (tinja) kehitaman dan feses mengeras (Naviri, 2011). Dengan demikian konsumsi tablet Fe dapat menyebabkan konstipasi pada ibu hamil, ditambah adanya relaksasi otot halus dari usus besar dengan adanya jumlah progesteron yang meningkat, pergeseran dan penekanan terhadap perut oleh uterus yang membesar pada ibu hamil mungkin juga penyebab tambahan dalam gerak kerja yang menurun dalam saluran pencernaan sehingga defekasi yang jarang dan jumlah feses yang kurang yang konsistensinya keras dan kering. Yang sering mengalami konstipasi wanita hamil selama trimester kedua dan ketiga (Piego, 2004).

Berdasarkan fakta dan teori yang telah dipaparkan sebelumnya dapat ditarik kesimpulan bahwa keteraturan dalam mengkonsumsi tablet Fe sangat berhubungan dengan kejadian konstipasi pada ibu hamil. Dari data diatas ibu yang mengkonsumsi tablet $\mathrm{Fe}$ secara teratur hampir seluruhnya mangalami kejadian konstipasi dan sebagian kecil dari ibu yang tidak teratur dalam konsumsi tablet Fe tidak mengalami konstipasi pada kehamilan. 
Sehingga perlu adanya aktivitas ringan namun teratur dan keteraturan dalam konsumsi makanan berserat misalnya sayur-sayuran dan buah-buahan yang sangat penting bagi ibu yang mengkonsumsi tablet $\mathrm{Fe}$ agar dapat mengurangi konstipasi selama masa kehamilan.

\section{Kesimpulan}

Dari hasil data pada penelitian dan pembahasan diatas maka dapat ditarik kesimpulan antara lain sebagai berikut:

a. Konsumsi tablet $\mathrm{Fe}$ ibu hamil di Desa Bandar Kecamatan Bandar Kabupaten Pacitan sebagian besar 19 $(57,5 \%)$ mengkonsumsi tablet fe secara teratur.

b. Kejadian konstipasi ibu hamil di Desa Bandar Kecamatan Bandar Kabupaten Pacitan sebagian besar 18 $(54,5 \%)$ mengalami konstipasi.

c. Ada hubungan konsumsi tablet fe dengan kejadian konstipasi pada ibu hamil di desa bandar kecamatan bandar kabupaten pacitan dengan hasil uji statistik $p=0,000$ sehingga nilai $p$ yang didapat adalah kurang dari 0,05 .

\section{Saran}

a. Bagi Institusi

Sebagai sumber pustaka atau referensi tentang konsumsi tablet $\mathrm{Fe}$ secara teratur, baik dan benar.

b. Bagi Profesi

Sebagai salah satu sumber informasi untuk penelitian selanjutnya dan pengembangan profesi kebidanan di masa mendatang.

c. Bagi Peneliti

Guna menambah pengetahuan tentang konsumsi tablet $\mathrm{Fe}$ secara teratur, baik dan benar sehingga dapat melakukan intervensi yang lebih tepat guna menghindari kejadian konstipasi.

d. Bagi Ibu Hamil

Dengan adanya penelitian diharap ibu hamil dapat mengerti mengenai konsumsi tablet $\mathrm{Fe}$ secara teratur, baik dan benar sehingga dapat memenuhi kebutuhan zat besi bagi ibu tanpa terjadi konstipasi.

\section{DAFTAR PUSTAKA}

Almatsier, S. 2001. Prinsip Dasar Ilmu Gizi, Jakarta: Gramedia Pustaka Umum.

Arikunto, S 2003. Prosedur Penelitian. Jakarta : Rineka Cipta

Farmakope edisi III. 1995. Pengertian Tablet. Jakarta: Balai Penerbit EGC.

Heru, 2014. Teknik Sampling Untuk Penelitian Kesehatan. Jakarta: Balai Penerbit Graha Ilmu.

Hidayat, A. Azis Alimul 2006. Kebutuhan Dasar Manusia I. Jakarta: Salemba Medika.

Jordan, S. 2004. Farmakologi Kebidanan. Jakarta: EGC.

Krisnatuti dan Yenrina. 2001. Menyiapkan Makanan Pendamping ASI. Jakarta: Pustaka Swara.

Marissa. Dkk. 2008. Hubungan Antara Intensitas Pemeriksaan Kehamilan, Fasilitas Pelayanan Kesehatan Dan Konsumsi Tablet Besi Dengan Tingkat Keluhan.

Moh. Nazir, 2005, Metodologi Penelitian. Jakarta: Ghalia Indonesia

Naviri, Dkk. 2011. Buku Pintar Ibu Hamil. Jakarta: Elex Media Komputindo.

Nursalam. 2001. Konsep dan Penerapan Metodologi Riset Penelitian Ilmu Keperawaatan. Jakarta : Salemba.

Nursalam. 2005. Konsep dan Penerapan Metodologi Riset Penelitian Ilmu Keperawaatan. Jakarta : Salemba.

Notoatmodjo, S. 2002. Pendidikan dan Perialaku Kesehatan. Jakarta : Penerbit Rineka Cipta.

Pusdiknakes. 2003. Tablet Zat Besi. Jakarta: EGC.

Piego, J. H. 2004. Asuhan Antepartum. Jakarta: WHO.

Paath, E. F. 2004. Gizi Dalam Kesehatan Reproduksi. Jakarta: EGC.Sherry, J. 2000. Kehamilan Yang Menyenangkan. Jakarta: Arcan

WHO, 2007. Ibu Hamil Dengan Kekurangan Zat Besi. Jakarta: EGC. 